Gut, 1988, 29, 1557-1563

\title{
Age related increase of brush border enzyme activities along the small intestine
}

\author{
F RAUL, F GOSSE, M DOFFOEL, P DARMENTON, AND J Y WESSELY
}

From the Unité de Biologie Cellulaire et de Physiopathologie Digestives, INSERM U61, Strasbourg, France and Laboratories CERNEP-Synthelabo, Le Plessis Robinson, France

SUMMARY Intestinal morphology and brush border hydrolase activities were determined along the small intestine of young adult (three months, $n=10)$, mature (12 months, $n=10)$, and senescent (29 months, $n=15$ ) rats. The intestinal segments of the senescent rats contained higher mucosal mass and protein content $(\mathbf{p}<0.05)$ compared with the young and mature animals. A significant reduction of villus height and crypt depth $(\mathbf{p}<0.05)$ was found in the proximal intestine during aging. A $35 \%$ increase in villus height $(\mathbf{p}<0.05)$ without changes in crypt depth, was observed in the distal ileum in senescent rats. The activities of sucrase and isomaltase were significantly increased during aging in the duodenum and jejunum $(\mathbf{p}<0 \cdot 05)$. Lactase and aminopeptidase activities which showed only minor changes between young and mature animals were significantly enhanced in senescent animals $(p<0.05)$ with aminopeptidase exhibiting a three-fold increase in activity in the proximal ileum. The results when combined with those of previous studies suggest that in the aged animal, the increased level of intestinal hydrolase activities may be the consequence of prolonged cellular maturation along the villi in the proximal intestine, and of adaptation to increased concentrations of intraluminal substrates in the distal intestine.

A spectrum of changes occurs in the function of the gastrointestinal tract throughout the life of the animal. ${ }^{1}$ In contrast with other systems, however, such as the cardiovascular system, in old age the gastrointestinal tract does not reveal dramatic structural and functional deteriorations which might be expected to arise from the body's aging process. Aging has been shown to cause a reduction in pancreatic digestive enzyme content, but the residual activities are sufficient to allow digestion to proceed normally. ${ }^{2}$ In the intestine it is controversial whether aging is associated with important morphological or functional changes. For example, it has been reported that the length of the villi is either reduced or increased during aging depending on the intestinal segment and on the species studied..$^{36}$ The activity of the digestive enzymes located in the brush border membranes has been shown to be reduced, ${ }^{378}$ maintained, ${ }^{9}$ or increased ${ }^{6}$ in old age. In order to gain

Address for correspondence: Dr Francis Raul, INSERM, Unité 61, 3, avenue Molière, 67200 Strasbourg, France.

Received for publication 1 June 1988. better insight in the changes occurring in the functional capacities of the small intestine during aging, we have examined the activity of various brush border hydrolases at several locations along the entire small intestine of young adult (three months), mature (12 months), and senescent ( 29 months) rats.

\section{Methods}

ANIMALS

The studies were carried out with male Wistar rats originating from the breeding laboratories $\mathrm{R}$ Janvier (St Berthevin, France). The animals were obtained at least one month before the experiments began and were housed in individual metabolic cages. All rats were fed the same standard laboratory chow containing $20 \%$ protein and $55 \%$ carbohydrates (UAR, Villemoisson sur Orge, France). The food consumption was assessed, and all studies were done on unfasted animals. The various groups consisted of three month (young adults), 12 month (mature), and 29 month (senescent) old rats. Young and mature 
rats ate daily 20 to $25 \mathrm{~g}$ of pelleted food and senescent rats ate 14 to $18 \mathrm{~g}$ of the same food.

REMOVAL OF TISSUES

The rats were killed between 0900 and 1000 hours. The abdominal cavity was opened and the pyloroduodenal and ileocaecal junctions were cut. The small intestine was flushed with cold saline and excised. The total length of the small intestine was determined by vertical suspension with an attached $3 \mathrm{~g}$ weight. From each animal four intestinal segments were taken along the small intestine for mucosal weight determination, histological examination, and enzyme assays. The duodenal segment extended from the pyloroduodenal junction to the ligament of Treitz. The segment corresponding to proximal jejunum comprised the first $10 \mathrm{~cm}$ of the jejunoileum extending from ligament of Treitz. The proximal ileum consisted of a $10 \mathrm{~cm}$ segment extending from the middle of the jejunoileum, and the segment of distal ileum was the last $10 \mathrm{~cm}$ before the ileocaecal valve.

HISTOLOGICAL METHODS

Pieces of $1 \mathrm{~cm}$ length were removed in each segment for histological examination. The pieces were taken at the proximal extremities of the various segments. After fixation in Bouin's solution, the pieces were dehydrated and embedded in paraffin. Sections $5 \mu \mathrm{m}$ thick were stained with haematoxylin and eosin. The heights of the crypt-villus columns were measured in a minimum of 25 columns in which crypt and villus were well oriented in a sagittal plane. The villus height was taken as the distance from crypt-villus junction to villus tip and crypt depth corresponded to the distance from crypt-villus junction to the bottom of the crypt. The measurements were obtained with a semi-automatic image analyser (MOP/AM 01 System).

\section{BRUSH BORDER PURIFICATION AND ENZYME} ASSAYS

The mucosa of the various segments was scraped, weighed and homogenised in $50 \mathrm{mM}$ mannitol, $2 \mathrm{mM}$
Tris ( $\mathrm{pH}: 7 \cdot 1)$. Brush border membranes were isolated from mucosal homogenates as described by Schmitz et al. ${ }^{10}$ Sucrase and isomaltase activities were assayed according to Dahlqvist. " Lactase was measured in the presence of p-chloromercuribenzoate. ${ }^{12}$ Aminopeptidase $\mathrm{N}$ was determined according to Maroux et $a^{l^{13}}$ using L-alanine-pnitroanilide as substrate. Proteins were assayed according to the method of Lowry et al. ${ }^{14}$ Enzyme activities were expressed as either specific activities in the purified brush border membranes $(\mathrm{mU} / \mathrm{mg}$ protein) or as total activities per centimetre length of the intestinal segment $(\mathrm{mU} / \mathrm{cm})$. One unit of activity equals $1 \mu \mathrm{mol}$ product formed per minute at $37^{\circ} \mathrm{C}$.

STATISTICAL ANALYSIS

Statistical analysis was performed with one-way analysis of variance followed by Student's $t$ test. A p value $<0.05$ was considered to be indicative of a significant difference between two mean values.

\section{Results}

EFFECT OF AGE ON WEIGHT, INTESTINAL

DIMENSION, AND PROTEIN CONTENT

The body weight of the rats increased constantly during aging from approximately $380 \mathrm{~g}$ in the young adult to $600 \mathrm{~g}$ in the senescent animal (Table 1). The total small intestinal length was remarkably stable at each age (Table 1). In all groups, the distal ileum exhibited lower mucosal mass. All along the small intestine of the senescent animals, the intestinal segments contained higher mucosal mass as compared with the three and 12 month old rats (Table 1).

The protein content of the jejunoileal segments was significantly increased in the older animals (Table 2). In contrast, only minor changes were noticed in the duodenum. As illustrated in Table 2, aging did not cause significant alterations in the protein content of the brush border membranes. The brush border protein yield for a given intestinal segment exhibited no significant age-related changes. The yield was of 3.6 to $4.2 \%$ in the duodenum, 3.8 to $4 \%$ in the proximal jejunum and 4 to $4 \cdot 2 \%$ in the

Table 1 Effect of age on body weight and intestinal dimensions

\begin{tabular}{lllllll}
\hline & & & \multicolumn{4}{l}{ Weight of mucosa in intestinal segments $(g)$} \\
\cline { 5 - 7 } Age $($ months $)$ & $\begin{array}{l}\text { Body weight } \\
(g)\end{array}$ & $\begin{array}{l}\text { Small intestinal } \\
\text { length }(\mathrm{cm})\end{array}$ & 1 & 2 & 3 & 4 \\
\hline $3(10)$ & $379(7 \cdot 4)^{*}$ & $130(3 \cdot 3)^{*}$ & $0 \cdot 49(0 \cdot 02)^{*}$ & $0 \cdot 55(0 \cdot 03)^{*}$ & $0 \cdot 45(0 \cdot 02)^{*}$ & $0 \cdot 40(0 \cdot 01)^{*}$ \\
$12(10)$ & $569(8 \cdot 4) \dagger$ & $131(3 \cdot 5)^{*}$ & $0 \cdot 48(0 \cdot 02)^{*}$ & $0 \cdot 59(0 \cdot 02)^{*}$ & $0 \cdot 42(0 \cdot 01)^{*}$ & $0 \cdot 41(0 \cdot 02)^{*}$ \\
$29(15)$ & $600(17 \cdot 7) \ddagger$ & $128(2 \cdot 9)^{*}$ & $0 \cdot 62(0 \cdot 03) \dagger$ & $0 \cdot 66(0 \cdot 03) \dagger$ & $0 \cdot 57(0 \cdot 03) \dagger$ & $0 \cdot 55(0 \cdot 02) \dagger$ \\
\hline
\end{tabular}

Values are means (SE) with number of rats in parentheses. Intestinal segments: $1=$ duodenum, $2=$ proximal jejunum, $3=$ proximal ileum, $4=$ distal ileum. For a given column means not sharing a common superscript symbol differ significantly. ${ }^{*} \neq \dagger \neq \neq p<0 \cdot 05$. 
Table 2 Effect of age on protein content of intestinal segment and brush border membranes

\begin{tabular}{|c|c|c|c|c|c|c|c|c|}
\hline \multirow[b]{2}{*}{ Age } & \multicolumn{4}{|c|}{ Total protein content of the intestinal segment ( $\mathrm{mg}$ ) } & \multicolumn{4}{|c|}{ Protein content of brush border membranes $(\mathrm{mg})$} \\
\hline & 1 & 2 & 3 & 4 & 1 & 2 & 3 & 4 \\
\hline 3 months (10) & $55 \cdot 1(2 \cdot 4)^{*}$ & $60 \cdot 5(2 \cdot 5)^{*}$ & $56 \cdot 3(1 \cdot 5)^{*}$ & $46 \cdot 2(2 \cdot 1)^{*}$ & $2 \cdot 2(0 \cdot 2)^{*}$ & $2 \cdot 3(0 \cdot 1)^{*}$ & $2 \cdot 4(0 \cdot 1)^{*}$ & $1.7(0.2)^{*}$ \\
\hline 12 months (10) & $61 \cdot 5(1 \cdot 9)^{*}$ & $71 \cdot 4(1 \cdot 3) \dagger$ & $57 \cdot 3(1 \cdot 6)^{*}$ & $53 \cdot 1(1 \cdot 7) \dagger$ & $2 \cdot 2(0 \cdot 2)^{*}$ & $2 \cdot 7(0 \cdot 2)+$ & $2 \cdot 3(0 \cdot 1)^{*}$ & $1.9(0 \cdot 1)^{*}$ \\
\hline 29 months (15) & $63 \cdot 7(7 \cdot 5)^{*}$ & $75.0(3.2) \dagger$ & $64 \cdot 8(3 \cdot 0) \dagger$ & $60 \cdot 4(3 \cdot 1) \dagger$ & $2.7(0.3)^{*}$ & $2.9(0.2) \dagger$ & $2 \cdot 6(0 \cdot 2)^{*}$ & $2 \cdot 2(0.2)^{*}$ \\
\hline
\end{tabular}

Values are means (SE) with number of rats in parentheses. Intestinal segments: $1=$ duodenum, $2=$ proximal jejunum, $3=$ proximal ileum, $4=$ distal ileum. For a given intestinal segment, means not sharing a common superscript symbol differ significantly. ${ }^{*} \neq \dagger<0 \cdot 05$.

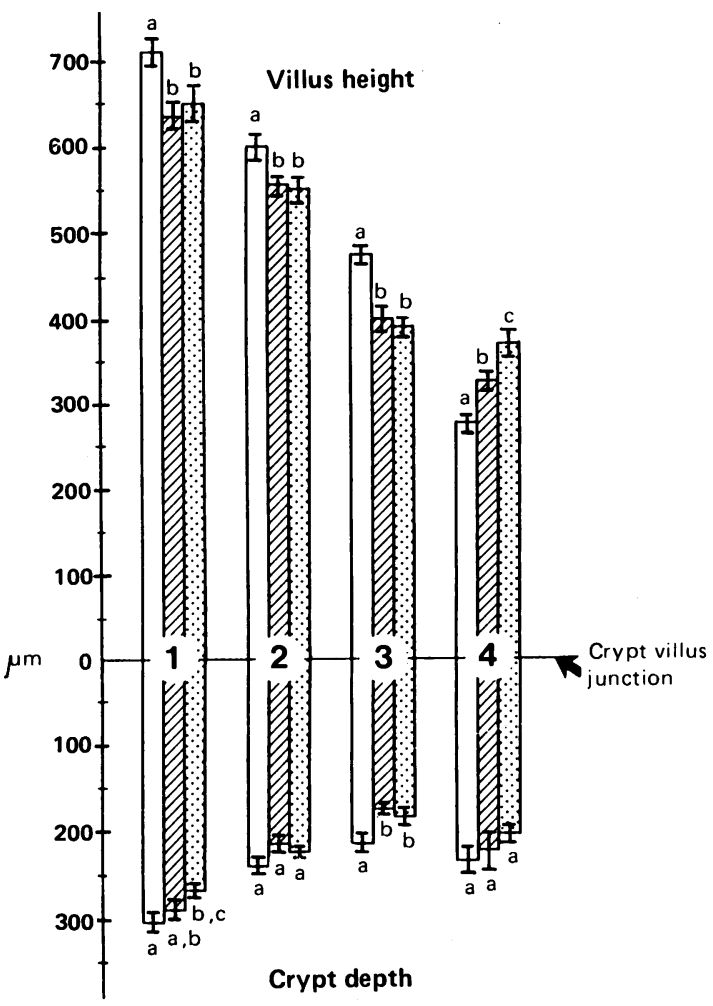

Fig. 1 Modifications in histologic dimensions along the small intestine during aging. Data from 10 to 15 animals in each group are presented as mean (SE). A minimum of 25 villus-crypt columns were measured in each animal. Intestinal segments: $1=$ duodenum; 2 =proximal jejunum; 3=proximal ileum; 4=distal ileum. $\square$ : young adults; $\mathbb{Z}$ :

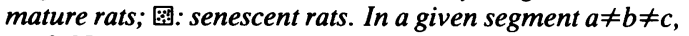
$p<0.05$.

proximal ileum. The lowest protein concentration was obtained in the brush border membranes of the distal ileum and the same protein yield $(3 \cdot 6 \%)$ was measured in all age groups.

EFFECT OF AGE ON INTESTINAL MORPHOLOGY A classical method of determining histological differ- ences in intestinal dimensions consist in measurements of villus height and crypt depth. As shown in Figure 1, in all age groups, an oral-aboral gradient was present so that the height of the villi constantly decreased from proximal to distal intestine and the gradient was more pronounced in the young adults.

A rapid reduction in the height of the villi was observed in animals older than three months. In the 12 month old rats, the shortening of the villi was about $10 \%$ in the duodenum and jejunum and reached $20 \%$ in the proximal ileum. No further alterations were observed in the senescent animal which showed a similar pattern in the proximal intestine as the 12 month old rat. It was noteworthy that aging caused an increase in the height of the villi in the distal part of the small intestine. Thus, in the senescent rat the height of the villi measured in the distal ileum was $35 \%$ taller than in the three month old rat (Fig. 1). Crypt depth showed a slight reduction after three months' of age in the proximal intestine, but no changes were observed during aging in the distal ileum.

DISTRIBUTION OF BRUSH BORDER ENZYMES ALONG THE INTESTINE

As shown in Figures 2 and 3, a similar pattern of enzyme distribution was found along the small intestine in young adult, mature, and senescent rats. Sucrase and lactase activities reached maximal activity in the proximal jejunum and then decreased constantly, reaching low values in the distal ileum. Isomaltase is associated with sucrase in the same enzyme molecule. In contrast with the sucrase activity, isomaltase exhibited highest activity in the proximal ileum. Aminopeptidase activity was predominant in the ileum.

\section{EFFECT OF AGE ON INTESTINAL HYDROLASE ACTIVITIES}

In order to avoid misinterpretation, it is very important to use a proper reference system for the expression of enzyme activities. The results presented here are expressed with two distinct denominators: either the protein content in the case of 

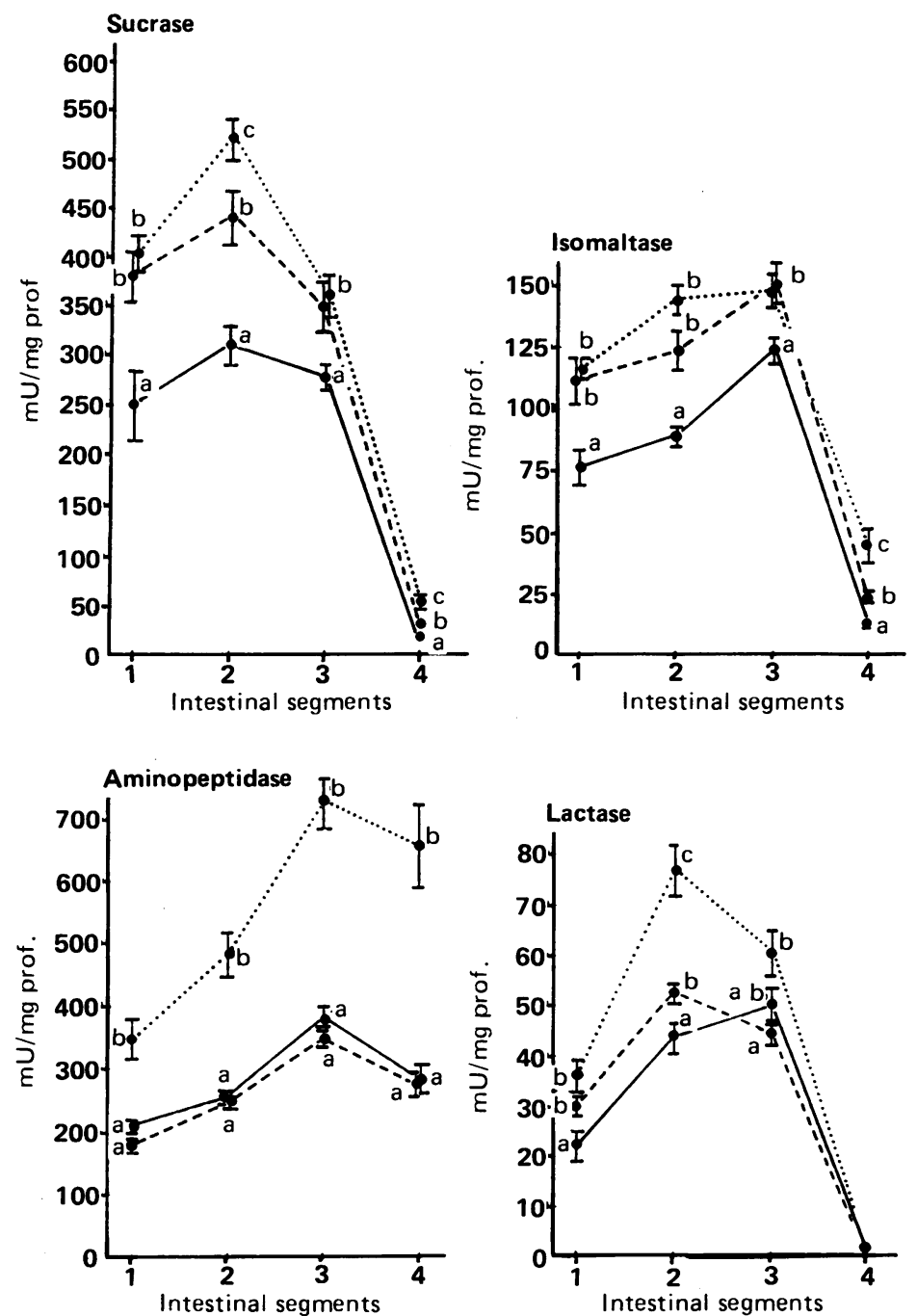

Fig. 2 Comparison of enzyme specific activities ( $m U / m g$ protein) in purified brush border membranes along the small intestine in young adult ( $(-)$ mature $(--)$ and senescent $(. . . .$.$) rats. Intestinal segments: 1=$ duodenum; $2=$ proximal jejunum; $3=$ proximal ileum; $4=$ distal ileum. For a given intestinal segment, comparison between the groups $a \neq b \neq c, p<0.05$.

specific activity in purified brush border membranes (Fig. 2) or intestinal length in the case of total activity in mucosal homogenates (Fig. 3). The total activity per intestinal length is directly related to the functional capacity of the intestinal segment whereas changes in specific activities might be influenced by variations in the protein content of the brush border membrane. Nevertheless, it is clear that when the activity of a given enzyme is enhanced in both reference systems, it is then the consequence of a corresponding increase in enzyme equipment. We show that in both reference systems the activities of sucrase and isomaltase were significantly higher during aging in the duodenum and in the proximal jejunum (Figs 2 and 3). Sucrase and isomaltase were increased in the 12 month old rats but exhibited their highest activities in the intestine of the senescent rats. Lactase activity showed only minor modifications between three months and 12 months of age and was significantly higher in the jejunum and proximal ileum of the 29 month old rats (Figs 2 and 3). Aminopeptidase activity expressed in both reference systems showed no significant variations between young and mature animals and was strikingly 

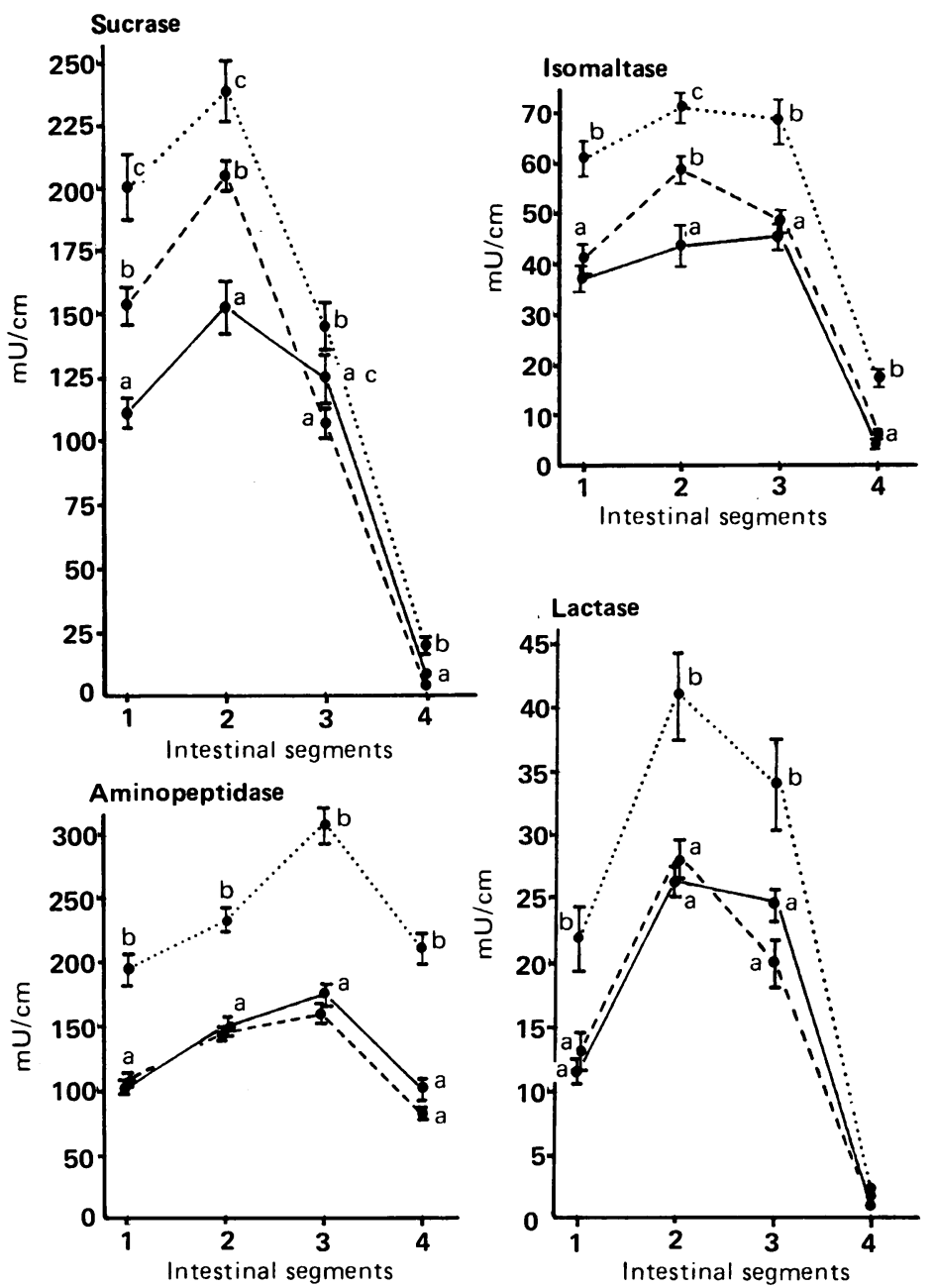

Fig. 3 Effect of aging on total enzyme activities $/ \mathrm{cm}(\mathrm{mU} / \mathrm{cm})$ in the various segments along the small intestine. For further details see legend of figure 2 .

enhanced all along the intestine of the senescent rats but kept during aging the same oral-aboral distribution pattern (Figs. 2 and 3).

\section{Discussion}

Our results show that aging provokes an increase in the activity of the hydrolases located in the intestinal brush border membranes of the senescent animals as compared with younger rats.

The increase in the body weight obtained from three to 29 months of age is similar to that reported previously by other investigators for Wistar rats. ${ }^{15}$ Information on the relative changes in size and length of the small intestine during aging is scarce. Our data, indicating that the total small intestinal length of three, 12 , and 29 month old rats remains virtually unchanged are in agreement with those obtained previously by Penzes. ${ }^{16}$ The present report indicates that the mucosal mass of the intestine and the mucosal protein content are increased in the senescent rat. These results, which corroborate well with previous findings obtained in mice $^{6}$ and Fischer rats, ${ }^{4}$ might be the consequence of the increased submucosa and villi thickness observed with age.

The changes which occur with aging to the absorptive surfaces of the intestine show important differences between the proximal and distal regions. We show that the height of the villi is reduced with age in the duodenum and jejunum. The shortening of the 
villi occurs during the first year of life.$^{17}$ In contrast, we found a $35 \%$ increase in the length of the villi in the distal ileum of senescent animals as compared with young adults. Similar results have been reported recently in Fischer rats. ${ }^{4}$

In the proximal intestine the villus atrophy obtained during aging might be related to a diminution in the rate of epithelial renewal as indicated by the corresponding reduction of crypt size. A delayed generation time for the epithelial cells has been previously reported in old animals. ${ }^{318}$ Interestingly, these age related changes in the rate of epithelial cell proliferation observed in the proximal intestine have not been noted in the ileum ${ }^{19}$ where we found no changes in crypt depth. The longer generation time in the proximal intestine may well be associated with less extrusion of cells from the villus tip and with a population of more mature epithelial cells lining up the villi. Increased cellular maturation caused by a slower transit rate of the cells along the villi has been previously reported in sucklings and in nutritionally deprived infant rats..$^{201}$

We show that aging is associated with a rise in disaccharidase and aminopeptidase activities in the intestine of older animals. At first glance, these results seem to be in conflict with other studies indicating that the activities of intestinal enzymes were significantly reduced during aging. ${ }^{68}$ The discrepancy may arise from the way enzyme activity is expressed or the type of material used for the enzyme assays (total homogenates or purified brush border membranes). In fact, because mucosal weight and protein content is higher in the older animals, an apparent reduction in enzyme activity will be obtained when enzyme activity is referred either to mucosal weight or to protein content (specific activity). When enzyme activity is expressed as total activity, however, the same results clearly show a maintenance of an increase in intestinal enzyme activity during aging. ${ }^{67}$ Furthermore, we have also measured enzyme activity in purified brush border membranes which exhibited only minor variations in their protein content between the three age groups. A significant increase in the specific activity of the disaccharidases and aminopeptidase was obtained along all the small intestine during aging. As discussed above, in the proximal intestine of senescent rats, the increased enzyme activities in the brush border membranes might be directly related to the presence of more mature epithelial cells lining up the villi as a consequence of reduced cellular transit rate. A similar explanation does not seem to be adequate in order to explain the increased enzyme activities measured in the distal ileum of older animals. In contrast with the duodenum and jejunum, the distal ileum of the senescent animal exhibited no age related changes for villus-crypt architecture. It has been shown that absorption is impaired in the proximal intestine of aged animals. ${ }^{5}{ }^{15} 1622$ Thus, when absorption in the proximal intestine is decreased, a greater amount of nutrients will be present in the lumen of the ileum. Consequently, increased concentrations of substrates in the lumen will cause ileal hypertrophy and stimulation of brush border hydrolase activities. ${ }^{23}$ In older animals, increased hydrolase activities in the ileum might be related to substrateinduced enzyme stimulation originating from the increased availability of intraluminal substrates. Because aging rats consumed $20 \%$ less chow than young animals, the adaptive response of the ileum was not caused by greater food intake.

The present results taken together with previous studies suggest that aging might initiate mainly two types of adaptive responses in the small intestine. In the proximal intestine (duodenum and jejunum), the functional capacities of the epithelial cells might be increased as a consequence of prolonged maturation of these cells along the villi. In the distal part of the intestine (ileum), the enhanced capacity to digest disaccharides and peptides might be a consequence of adaptation to increased concentrations of intraluminal substrates in order to compensate for the reduced absorptive capacity of the jejunum in the aged animal.

The authors would like to thank Mr M Galluser and Misses $\mathrm{V}$ Visbeq and $\mathrm{MH}$ Ferrer for excellent technical assistance.

\section{References}

1 Thomson ABR, Keelan M. The aging gut. Can J Physiol Pharmacol 1986; 64: 30-8.

2 Snook JT. Effect of age and long term diet on exocrine pancreas of the rat. Am J Physiol 1975; 228: 262-8.

3 Höhn P, Gabbert H, Wagner R. Differentiation and aging of the rat intestinal mucosa. II. Morphological, enzyme-histochemical and disc electrophoretic aspects of the aging of the small intestinal mucosa. Mech Ageing Dev 1978; 7: 217-26.

4 Holt PR, Pascal RR, Kotler DP. Effect of aging upon small intestinal structure in the Fischer rat. J Gerontol 1984; 39: 642-7.

5 Jakab L, Penzes L. Relationship between glucose absorption and villus height in aging. Experientia 1981; 37: 740-1.

6 Moog F. The small intestine in old mice. Growth, alkaline phosphatase and disaccharidase activities, and deposition of amyloid. Exp Gerontol 1977; 12: 223-35.

7 Holt PR, Tierney AR, Kotler DP. Delayed enzyme expression: a defect of aging rat gut. Gastroenterology 1985; 89: 1026-34.

8 Rommel K, Böhmer R. Beziehungen zwischen 
Lebensalter, intestinalen disaccharidasen und Monosaccharidabsorption der Ratte. Arzneim Forsch 1972; 26: 453-7.

9 Welsh JD, Poley JR, Bhatia M, Stevenson DE. Intestinal disaccharidase activities in relation to age, race, and mucosal damage. Gastroenterology 1978; 75: 847-55.

10 Schmitz J, Preiser H, Maestracci D, Ghosh BK, Cerda JJ, Crane RK. Purification of the human intestinal brush border membrane. Biochem Biophys Acta 1973; 92: 305-11.

11 Dahlquist A. Method for assay of intestinal disaccharidases. Anal Biochem 1964; 7: 18-25.

12 Koldovsky O, Asp NG, Dahlqvist A. A method for the separate assay of 'neutral' and 'acid' B-galactosidase in homogenates of rat small intestinal mucosa. Anal Biochem 1969; 27: 409-18.

13 Maroux S, Louvard D, Baratti J. The aminopeptidase from hog intestinal brush border. Biochim Biophys Acta 1973; 321: 282-95.

14 Lowry OH, Rosebrough NJ, Farr AL, Randall RJ. Protein measurements with the Folin phenol reagent. J Biol Chem 1951; 193: 265-75.

15 Esposito G, Faelli A, Tosco M, Orsenigo MN, Battistessa R. Age-related changes in rat intestinal transport of D-glucose, sodium, and water. Am J Physiol 1985; 249: G328-34.

16 Penzes $\mathrm{L}$. Intestinal response in aging: changes in reserve capacity. Acta Med Hung 1984; 41: 263-77.

17 Clarke RM. Effects of age on mucosal morphological and epithelial cell production in rat small intestine. J Anat 1977; 123: 805-11.

18 Lesher S, Sacher GA. Effects of age on cell proliferation in mouse duodenal crypts. Exp Gerontol 1968; 3: 211-7.

19 Fry RJM, Lesher S, Kohn HI. Influence of age on transit time of cells of mouse intestinal epithelium. III. Ileum. J Lab Invest 1962; 11: 289-93.

20 Hatch TF, Lebenthal E, Branski D, Krasner J. The effect of early postnatal acquired malnutrition on intestinal growth, disaccharidases and enterokinase. J Nutr 1979; 109: 1874-9.

21 Tsuboi KK, Kwong LK, Neu J, Sunshine P. A proposed mechanism of normal intestinal lactase decline in the postweaned mammal. Biochem Biophys Res Commun 1981; 101: 645-52.

22 Geokas MC, Haverback BJ. The aging gastrointestinal tract. Am J Surg 1969; 117: 881-92.

23 Williamson $\mathrm{RCH}$. Intestinal adaptation: structural, functional and cytokinetic changes. N Engl J Med 1978; 298: $1393-402$. 